\title{
Fabrication and Optimization of Electrophoretic Deposition Parameters Using Alternating Current by Taguchi Design
}

\author{
Muna Khethier Abbass ${ }^{1}$, Mohammed Jasim Khadhim², Ayad Naseef Jasim³ ${ }^{3}$, Muhammad Jawad \\ Issa $^{4}$ and Khawla S. Khashan ${ }^{5}$
}

\section{Author's affiliations:}

1,2) Department of Production Engineering and Metallurgy/University of Technology, Iraq. 1)mukeab2014@yahoo.com 2)alimohammed@yahoo.com

3)College of Engineering, University of Diyala \& Dept of Production Eng. and Metallurgy, University of Technology, Baghdad, Iraq . 3)ayadalsmart@gmail.com

4) College of Veterinary Medicine, University of Baghdad, Baghdad, Iraq Mohammed.jowad1956@gmail. com

5)Application Science Department, University of Technology, Baghdad, Iraq khawla-salah@yahoo.come

\section{Paper History:}

Received: $16^{\text {th }}$ Feb. 2020

Revised: 29th March 2020

Accepted: 23 ${ }^{\text {rd }}$ Jan. 2021

\section{Abstract}

The aim of this work is to optimize EPD variables (voltage, time, and focus) using alternating current through the Taguchi Design of Experiment (DOE). Coating Nano hydroxyapatite (Nano-HA) on a Ti6Al4V substrate depends on thickness and roughness, then characterization of a coating layer to determine the optimum state. Hydroxyapatite (HAp) powder was deposited on a Ti-6Al-4V alloy substrate by electro-deposition with ethanol as a solvent under AC current, to improve the alloy surface quality based on coating thickness and maximum coating mass meeting the requirements of a biological orthopedics application. Ethanol was used as a solvent to precipitate ketazone and HAp on the base alloy. Taguchi's approach was used in order to determine the optimal conditions for EPD and subsequently to apply various criteria for depositing the biochemical coating. The surface and cross-section composition of the paint is described by characterization. Numerous tests and inspections; Zeta, XRD and SEM stability test, water contact angle and optical microscopes were used to describe the surface morphology of the HAp layer. The value of the optimum conditions for deposition of the HAp layer which is a simultaneous thickness and maximum coating mass, was predicted at a sedimentation voltage of $40 \mathrm{~V}, 2 \mathrm{~min}$ sedimentation time and $1 \mathrm{~g} / \mathrm{L}$ for the concentration of the suspended solution at room temperature. The validity of the model resulting from the response surface methodology was assessed by comparing the expected results with the experimental results. In addition, close agreement was observed between the experimental results and the expected results. For the solution at room temperature, the results obtained with the highest value of the coating thickness of 41 at the surface roughness of 0.94 and the contact angle of the alloy before coating is $67.489^{\circ}$ reduced to. $38.132^{\circ}$ after plating, which indicates an increase in the harmony of the metal implant and biocompatibility.

Keywords: Ti6Al4V alloy, Roughness, AC Current. Electrophoretic deposition, Nano hydroxyapatite, Taguchi design.

$$
\begin{aligned}
& \text { تصنيع وتحسين عوامل الترسيب الكهربي باستخدام التيار المتناوب بواسطة } \\
& \text { Taguchi تصميم } \\
& \text { منى خضير عباس، محمد جاسم كاظم ، اياد نصيف جاسم ، محمد جواد عيسى ، خولة صلاح خشان } \\
& \text { الملاصة: - n } \\
& \text { الهيف من هذا العمل هو تحسين متغيرات EPD( الجهد والوقت والتزكيز) باستخدام التيار المتناوب من }
\end{aligned}
$$

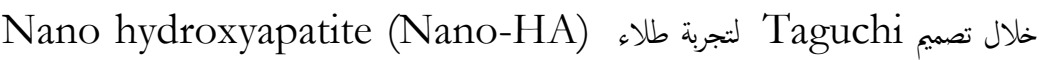

$$
\begin{aligned}
& \text { على الركيزة Ti6Al4V يعمد على السمك والحنشونة ، ثم توصيف طبقة طلاء لتحديد الحالة المثلى. تم }
\end{aligned}
$$

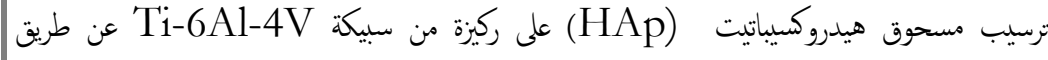

$$
\begin{aligned}
& \text { الترسيب الكهبئي باستخدام الإيثانول كذيب تحت تيار التيار المتزدد ، لتحسين جودة سطح السبيكة بناءً }
\end{aligned}
$$




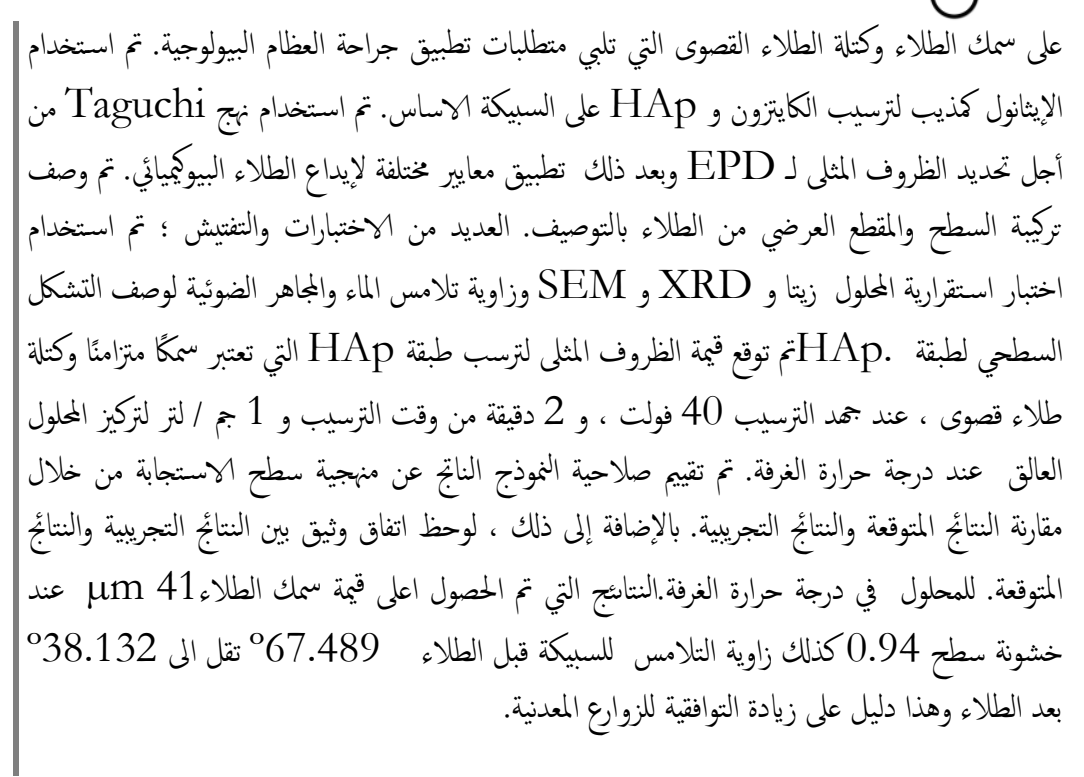

\section{Introduction}

Nowadays artificial biomedical prosthesis as well as implants of standard surgical grade materials such as 316L stainless Steelco-Cr alloys, titanium (Ti) and its alloys is extensively used in the field of orthopedics and dentistry. Ti-6Al-4V implants are mainly used as metal substrate due to its many attractive as well as accept-able physical, mechanical and biological properties [1], Ti6Al4V alloy has higher biocompatibility than AISI 316L and cobaltbased alloy. This is return to the superior corrosion resistance of the Ti alloy than the other types referred to formerly [2]. The chemical compositions on the surface and its topography are supposed to be essential in implants contacting bone [3]. Ti6Al4V alloys received great interest in biomedical field applications.

In both the dental and medical fields, an excellent balance in their excellent mechanical properties, excellent corrosion resistance, light weight, and excellent biocompatibility is needed . It is mainly used in implant systems for failed hard tissue changes, for example, dental implants, bone plates and artificial hip joints. Titanium and its alloys are recognized in Ti6Al4V for high tensile strength and corrosion resistance to drilling [4,5]. Materials Ti-6Al-4V has good mechanical properties Biomedical application, which is biocompatibility, Non-magnetic, high yield and tensile strength, excellent corrosion resistance, low Young Modulus and capability of fast osteointegration in the human body environment by rapidly forming $\mathrm{TiO} 2 / \mathrm{OH}$ film on the surface of bones [6]. Ti6Al4V alloy with $\alpha+\beta$ phases, which suitably treated, have an exceptional mixture of strength and ductility. They usually are stronger than the $\alpha$ or the $\beta$ alloy individually [7]. In recent years, research and development in the area of synthesis and applications of different nanostru cured $\mathrm{TiO}_{2}$ materials has greatly increased. Examples of applications of hydrogen production and storage, ensors, rechargeable batteries, electro catalysis and self-cleaning and antibacterial surfaces [8]. Pure and densified alumina, $\alpha-\mathrm{Al} 2 \mathrm{O} 3$ (corundum), was the first ceramic material used in the biomedical field for dental restorations, cochlear implants, and loadbearing hip prostheses. As porous alumina does not degrade under in vitro and in vivo environments, it may be used for bio sensing, and good electrical insulation [9].

Hydroxyapatite (HA) is considered the main inorganic component of Human bone and teeth) have been widely applied as coating On various medical bones and dental implants Improve biocompatibility and bioactivity [10]. It is considered $\mathrm{HA}$ as an excellent option for painting accrued metal implants to hyperactivity as well as a pattern to Formation and growth of adjacent bone tissue [11]. Hydroxyapatite (HAp) materials have drawn great interest from researchers because they are widely applied as biomedical materials, including such uses as bone fillers [12] However, pure HAP suffers from weak mechanical properties [13]. In contrast to HAP, Ti6Al4V alloy is confirmed to be appropriate material for load bearing requests [14]. Hence, the idea of Ti6Al4V alloy coating with HAP combines the benefits of both substances [15]. Among the different techniques of formation for HA coating (such as plasma spray, sol gel, Particle beam irradiation, pulsed laser deposition Electrochemical deposition), the electrochemical deposition method has many advantages, including low processing temperature, application to complex shapes, and Because of EPD a simple and low cost method therefore it is widely used as coating way $[16,17]$. In the following years the EPD became mainly used in the treatment of traditional ceramics, including enamel and porcelain, and very limited work on the EPD was made of engineering ceramics [18]. Electrophoresis (EPD) has been chosen as the coating method since the simplicity of manufacture, relatively low cost, and the ability to paint objects with sophisticated design. In this method, the cathode and anode trough electrical

NJES is an open access Journal with ISSN 2521-9154 and eISSN 2521-9162

This work is licensed under a Creative Commons Attribution-NonCommercial 4.0 International License 
current is used within the HAp suspension. The potential (voltage) will transfer the small particles of HAp to deposit on the surface of Ti6Al4V until an

equal layer of HAp coating is produced. This coating process requires several main parameters: voltage, concentration and times of coating. The required quality of HAp coating that can be produced can be achieved by adjusting these parameters [19]. The characteristics of EPD process depends on various parameters such as the electrical settings of the coating cells (deposition voltage), the electrical nature of electrodes, deposition time span and concentration of the suspension. According to Laxmidhar et al., the mass of the deposited particles, the thickness of the films can be directly controlled by concentration of the suspension, the deposition potential and the deposition time span. he impacts of these parameters on crystallization behavior needs to be investigated in order to find out optimal sets of conditions for HA layer deposition with desirable thickness and morphology [20].

Therefore, this study aims to optimize the EPD parameters including (deposition voltage, time and concentration of sushnpence) using alternating current by Taguchi design of the experiment method (DOE). On a Nano hydroxyapatite coating (Nano$\mathrm{HA}$ ) on the Ti6Al4V substrate dependent on thickness and roughness, an image-processing approach has been used to assess the uniformity and homogeneity of the coating. The optimum conditions were obtained using the signal-to-noise ratio $(\mathrm{S}=\mathrm{N})$ and the contribution rates were analyzed according to the ANOVA analysis. The output of this paper the raw data of responses are (roughness, thickness and porosity).

\section{Experimental Work \\ 2.1. Electrophoretic Deposition (EPD) Coating Process}

The materials used in this research prepared as a plate is Ti-6Al-4V (Company: Shanxi Joint industry co., ltd) which tested in Science and Technology Ministry by using analytical instruments model XEPOS and its name SPECTRO. Table 1 show the chemical composition of (Ti6Al4V) alloy, this result with standard, ASTM F136 - 13.

Table (1): Illustrates the chemical composition analysis of the used alloy

\begin{tabular}{|c|c|c|c|c|c|c|c|}
\hline Element & $\mathbf{A l}$ & $\mathbf{S i}$ & $\mathbf{C}$ & $\mathbf{V}$ & $\mathbf{F e}$ & $\mathbf{N i}$ & $\mathbf{T i}$ \\
\hline Standard\% & 6 & - & 0,08 & 4 & 0.25 & 0.05 & Bala. \\
\hline $\begin{array}{c}\text { Measured } \\
\text { \% }\end{array}$ & 5.94 & 0.09 & 89.3 & 4.05 & 0.25 & 0.3 & Bala. \\
\hline
\end{tabular}

Alloy plate, was cutting it to samples by wire cut machine with slow cutting speed and flow rate also used cutting fluid to avoid the heating result from the cutting. The thickness of the samples $5 \mathrm{~mm}$ and 20 $\mathrm{mm}$ length and $10 \mathrm{~mm}$ width determines according to the required test. One face of the samples was ground by $\mathrm{SiC}$ emery papers with 400, 600,800 and 1000 grit. Then they were cleaned in distilled water, and acetone ultrasonic bath for 15 minutes. The EPD suspension was prepared by using three concentrations 1,2 and $3 \mathrm{~g} / \mathrm{L}$ Hydroxyapatite (40 nm, purity of $99 \%$, white color with $3.140 \mathrm{~g} / \mathrm{cm} 3$ density) purchased from Sigma Aldrich was used to deposit it as a coating layers. Chitosan (medium molecular weight with a degree of de acetylation of about $85 \%$ soluble in $1 \%$ acetic acid with purity (>98\%) (purchased from Sigma Aldrich). It was used as a binder on Ti6Al4V and with HAp powders. The important step in the experimental procedure of EPD is to prepare the aqueous suspensions. The first step was dissolve $0.5 \mathrm{~g} / \mathrm{L}$ of chitosan using $1 \%$ acetic acid [21]. Then solvent was added with 5\% distilled water and then Nano powder of HAP materials were added. All suspensions were de agglomerated by a magnetically stirred. It was followed by a high-energy sonicator (Ultrasonic Processor, MIXSONIX Incorporated N.Y, USA) for $30 \mathrm{~min}$. $\mathrm{pH}$ meter with acetic acid was used to adjustment range of $\mathrm{pH}$ value 4 of solutions by using (pH-EC-TDS Meter Portugal). Zeta potential was measured for each solution to ensure its stability. The EPD cell used in this study consists of a beaker and two electrodes immersed in the suspension as schematic EPD system used in this study is shown in Fig. 1. ethanol solution. the EPD Instrumental involved from copper wire and digital power supply. The Ti-6Al-4V alloy and stainless steel $316 \mathrm{~L}$ were cathode and anode, respectively. The deposition process was take place through different deposition conditions concentration 1,2 and $3 \mathrm{~g} / \mathrm{L}$ times HAP 2,4 and 6 mint, voltages 20,40 and 60 volte. next, at room temperature, the samples coating was dried by air. The precipitation conditions (focus, time, and effort). were chosen, based on the Hamaker equation

where:

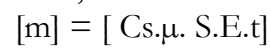

$\mathrm{m}=$ deposited mass $(\mathrm{g})$

$\mathrm{Cs}=$ suspension concentration $(\mathrm{g} \mathrm{cm}-3)$

$\mu=$ electrophoretic mobility (cm2 V-1 s-1)

$\mathrm{S}=$ deposition area $(\mathrm{cm} 2)$

$\mathrm{E}=$ electric field $(\mathrm{V} \mathrm{cm}-2)$

$\mathrm{t}=$ deposition time $(\mathrm{s})$

As for the specific values that were chosen so that the difference between the values is fixed in order to obtain accurate results

\subsection{Experimental design}

Taguchi's approach is a statistical tool of Experimental design. It was used to analyze data and for modelling the influences of different factors of EPD method on output whereas the inputs are described as factors while the outputs are described as response variables. This approach was used to determine optimal design parameters for performance and cost 


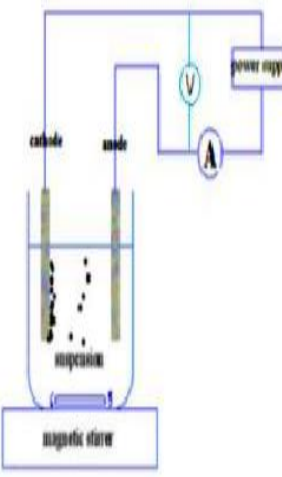

(a)

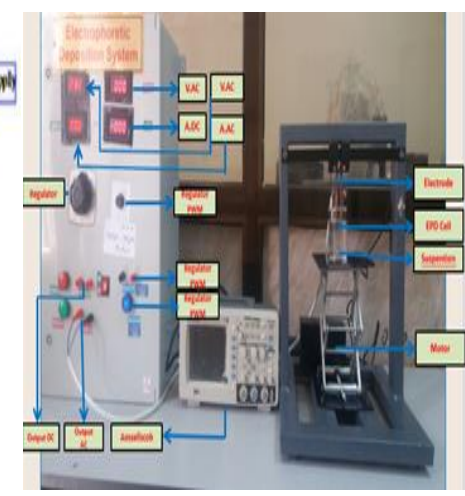

(b)
Figure (1): (a) EPD system diagram, (b)EPD system

The objective was to select the best combination of controlling parameters so that the Taguchi method was strongest with respect to noisily factors. In this study L9 (33) orthogonal array were used in experimental work to deposit hydroxyapatite layer, Table. 2 shows the experiments design according to Taguchi's approach and Table.3 shows the parameters of orthogonal array for HAP layer that used in design of experiments. The output of this paper (the raw data of responses are roughness, thickness and porosity).

Table (2): the parameters of HAP coating

\begin{tabular}{|l|l|l|l|}
\hline Voltage, $\boldsymbol{V}$ & 20 & 40 & 60 \\
\hline Time, min & 2 & 4 & 6 \\
\hline Concentration $\boldsymbol{C} \% \mathbf{g} / \boldsymbol{L}$ & 1 & 2 & 3 \\
\hline
\end{tabular}

Table (3):. L9 (33) Orthogonal Array for HAP layer

\begin{tabular}{|c|c|c|c|}
\hline Variables & $\begin{array}{c}\text { Voltage } \\
(\mathbf{v})\end{array}$ & $\begin{array}{c}\text { Time } \\
(\mathbf{m i n})\end{array}$ & Concentration(g/L) \\
\hline 1 & 1 & 1 & 1 \\
\hline 2 & 1 & 2 & 2 \\
\hline 3 & 1 & 3 & 3 \\
\hline 4 & 2 & 1 & 2 \\
\hline 5 & 2 & 2 & 3 \\
\hline 6 & 2 & 3 & 1 \\
\hline 7 & 3 & 1 & 3 \\
\hline 8 & 3 & 2 & 1 \\
\hline 9 & 3 & 3 & 2 \\
\hline
\end{tabular}

\subsection{Microstructure Characterization}

$\mathrm{X}$-ray diffraction analysis has been performed on Ti6Al4V alloy specimen to determine the existing phases. X-ray diffraction device used is (Lab X, XRD - 6000) with $40 \mathrm{Kv}$ and $30 \mathrm{~mA}$. Scanning speed $2^{\circ}$ per minute was used. The range of the diffraction angle was $\left(20^{\circ}-80^{\circ}\right)$. The thickness of coating and its morphology was examined by optical and scanning electron microscope. The distribution of elements at selected points/areas was detected by EDS detector. Zeta potential was necessary to study and analyze the stability of the suspension. This is one of the important tests in the EPD to ensure obtaining a homogeneous solution and thus ensure homogeneous coating layer. The particles were firstly dispersed in the corresponding solvent with a solid concentration lower than $1 \mathrm{~g} / 1$ to obtain reliable results by ultrasonic treatment for $15 \mathrm{~min}$. The results were ensured by the exposure of the suspension to the zeta potential measurement.

\section{3-Results and Discussion 3.1 Taguchi Results}

After the suspension preparation for HAp prepetition the statistical approach of Taguchi was utilized to choose the optimum conditions for HAp layer preparation on Ti6Al4V substrate. Since the HAP layer preparation aim was to gain the highest coating thickness. Thus the higher values of $\mathrm{V}, \mathrm{t}$ and $\mathrm{C}$ were choosing from signal -to- noise ratio $(\mathrm{S} / \mathrm{N})$ as the best one as illustrated in the table. 4 and fig. 2 the denoted above results were obtained according to Taguchi design (L9) for thickness measurement results for HAP layer using AC current, while table 5: Optimum condition of HAP coating Thickness, by using EPD with AC current.

Table (4): Signal-to-noise ratio for thickness coating

\begin{tabular}{|c|c|c|c|c|c|}
\hline No & $\begin{array}{c}\text { Voltage } \\
\mathbf{V}\end{array}$ & $\begin{array}{c}\text { Time, } \\
\text { min }\end{array}$ & $\begin{array}{c}\text { Concen } \\
\text { tration, } \\
\mathbf{g} / \mathbf{L}\end{array}$ & $\mathbf{S} / \mathbf{N}$ & $\begin{array}{c}\text { Mean } \\
\text { coating } \\
\text { thickness } \\
\boldsymbol{\mu m}\end{array}$ \\
\hline 1 & 20 & 2 & 1 & 27.58 & 24.333 \\
\hline 2 & 20 & 4 & 2 & 28.31 & 28.333 \\
\hline 3 & 20 & 6 & 3 & 33.17 & 28.666 \\
\hline 4 & 40 & 2 & 2 & 27.03 & 23.000 \\
\hline 5 & 40 & 4 & 3 & 30.07 & 32.333 \\
\hline 6 & 40 & 6 & 1 & 30.04 & 33.000 \\
\hline 7 & 60 & 2 & 3 & 32.22 & 41.000 \\
\hline 8 & 60 & 4 & 1 & 30.09 & 32.333 \\
\hline 9 & 20 & 2 & 1 & 29.65 & 30.666 \\
\hline
\end{tabular}

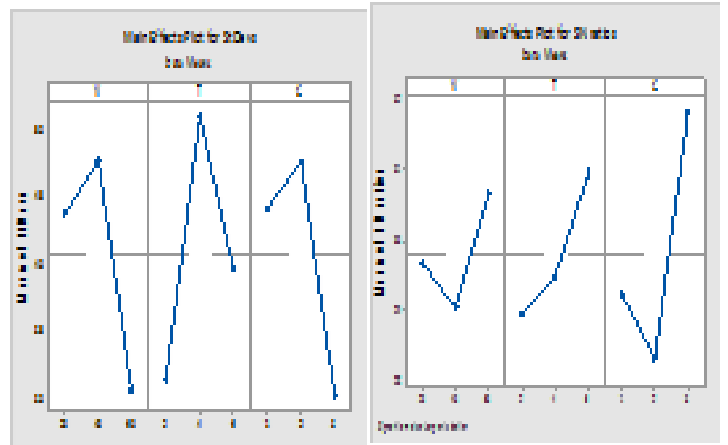

Figure (2): S/N ratio and means for thickness.

Table (5): Optimum condition of HAp coating

\begin{tabular}{|l|c|c|c|}
\hline Thickness, $\boldsymbol{\mu m}$ & $\begin{array}{c}\text { Voltage, } \\
\mathbf{V}\end{array}$ & $\begin{array}{c}\text { Time, } \\
\text { min }\end{array}$ & $\begin{array}{c}\text { Concentration, } \\
\mathbf{g} / \mathbf{L}\end{array}$ \\
\hline $\begin{array}{l}\text { Signal to Noise } \\
\text { Ratios (HAP) }\end{array}$ & 40 & 4 & 2 \\
\hline Means (HAP) & 60 & 6 & 3 \\
\hline
\end{tabular}

\subsubsection{Measurement of coating thickness}

The cross section of coating and its topography was examined with the of optical microscopy. The 
results of the examination are illustrated in the Fig. 3.

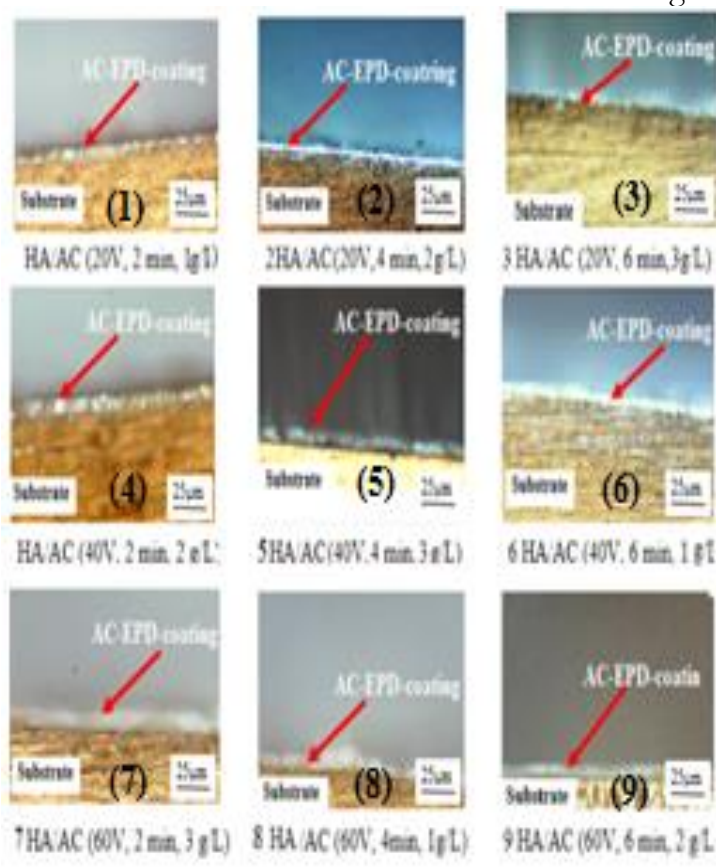

Figure (3): The cross-section of the coating layer(10X), the thickness of the coating of the samples $(1,2,3,4,----$ to 9$)$ are shown in Table 4.

The cross section of the coated sample at the optimum resulted conditions that give the highest coating thickness as show in Fig.4.

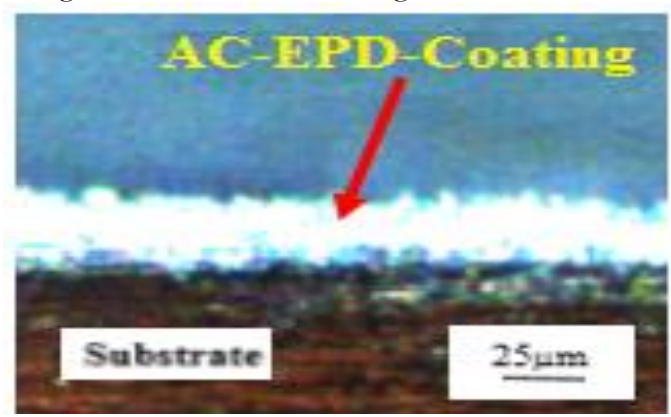

Figure (4): Cross section of the coated sample of $\mathrm{HA} / \mathrm{AC}$ with the used conditions $\mathrm{AC}(40 \mathrm{~V}, 4 \mathrm{~min}$, and $2 \mathrm{C} \%$ ) that gave the highest coating thickness

\subsection{X-ray diffraction analysis}

Fig. 5 shows the XRD analysis for Ti6Al4V alloy coated with Hap, and explains the peaks corresponding to the phase of hydroxyapatite such as (211) at $31.7^{\circ},(300)$ at $32.9^{\circ}$, (222) at $46.7^{\circ}$ and (213) at $49.4^{\circ}$ according to JCPDS card No 09-0432 .

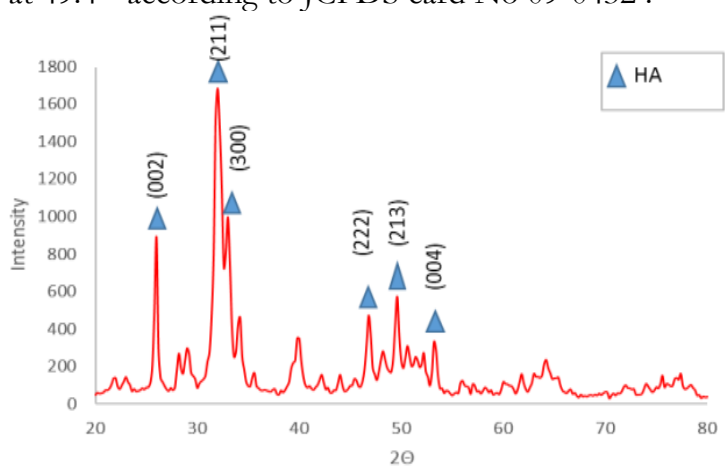

Figure (5): shows the XRD analysis for Ti6Al4V alloy coated with HA.

\subsection{Solution stability}

The measured of $\mathrm{pH}$ value of the suspension which was 4 lead to obtain Zeta potential with positive as depicted in the table 6 which enhance homogenies HAP precipitation. Increasing mobility by increasing absolute values of zeta potential. The high HAP particles mobility is return to the positive zeta potential value [16]. The zeta potential and mobility HAP nanoparticles are illustrated for the suspension of shown in Table 6 and Fig. 6

Table (6): The Zeta Potential and Mobility of HAP

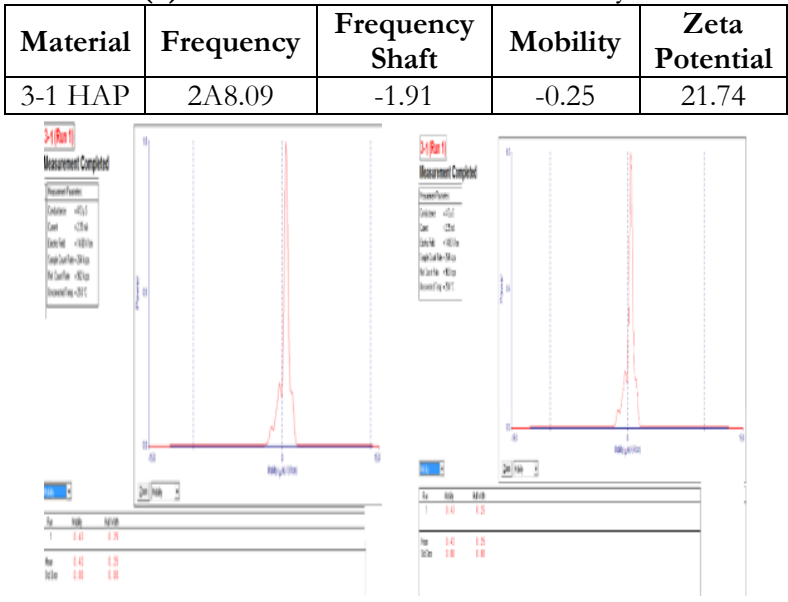

(a) Zeta potential

(b) Mobility

Figure (6): The Zeta Potential and Mobility of HAp

\subsection{Contact Angle Measurement}

The hydrophobicity or wet-ability of the coated Ti6A14V alloy and uncoated samples are measured using a steady drop of distilled water by measuring the solid and liquid contact angle via optical contact angle equipment type CAM 110-O4W which is attached with CCD camera. The coating led to decrease the contact angle from $75.448^{\circ}$ to $38.132^{\circ}$ which in turn converted the uncoated surface of the Ti6Al4V alloy from hydrophobic to hydrophilic. Surface coating was more hydrophilic in the HAp coating layer. In this case the bone regeneration will be easier and more rapt. When there are decreasing in contact angle with HAp coating is deposited on substrate coating. This resulted agreement with [17]. The above description of the contact angle values for un coated and coated Ti7AI4V alloy are shown in the fig. 7 .

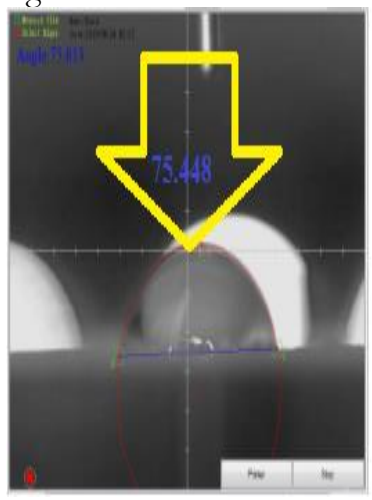

(a)

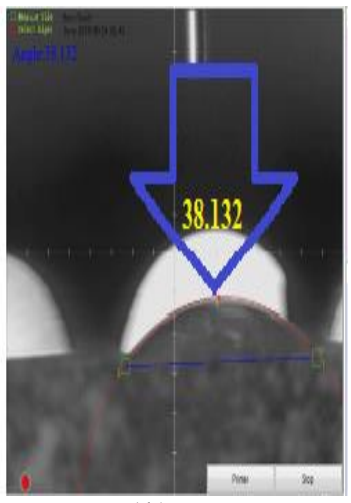

(b)
Figure (7): Water contact angle (a) Ti6Al4V Substrate uncoated. (b)Ti6Al4V Substrate coated with Hap 


\subsection{Microstructure and EDS analyses}

The study of morphology and cross section using a SEM and EDS are very important. Fig. 8 (a): Shows the EDS testing to the Ti6Al4V Substrate and Hap, while (b) shows the Morphology and coating thickness of the HAp coating thickness which is approximately equal to $25 \mu \mathrm{m}$. In the SEM coating is covering the whole substrate's surface and there aren't cracks indicated in the cross-sections, while there aren't any gaps between coatings as well as Ti6Al4V substrate, indicating that the bonding between Ti6Al4V and coating is sufficiently strong for resisting forces throughout implantation.
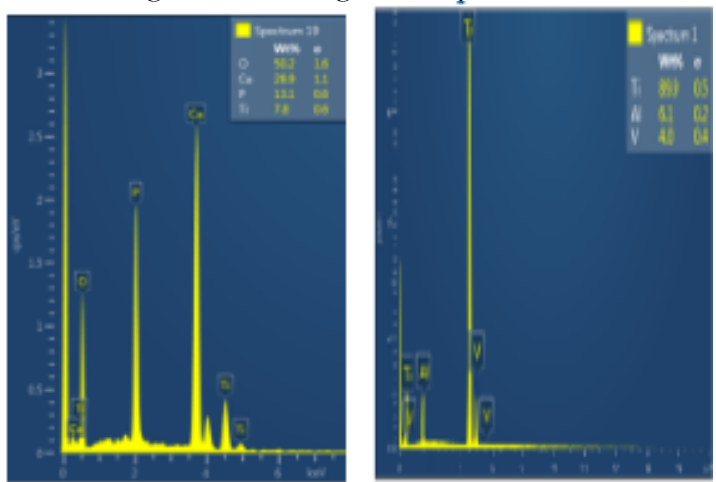

(a)
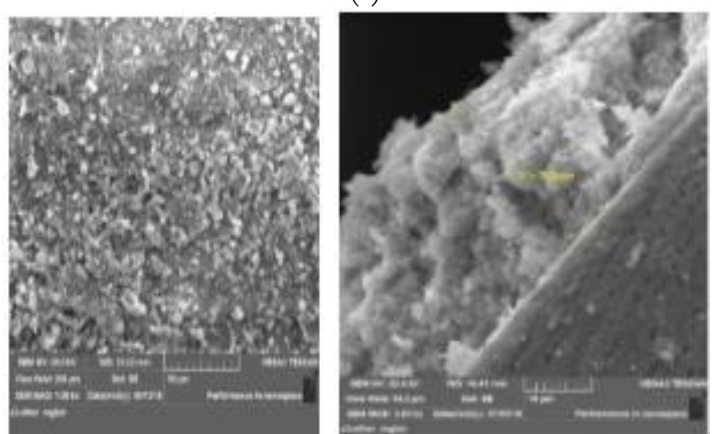

(b)
Fig. 9 Shows the microstructure of Ti6Al4V alloy which was observed by SEM and analyzed by EDS, and explain the structure is consisted of Alpha $(\alpha)$ and Beta $(\beta)$ and agreement with the composition of the used alloy.

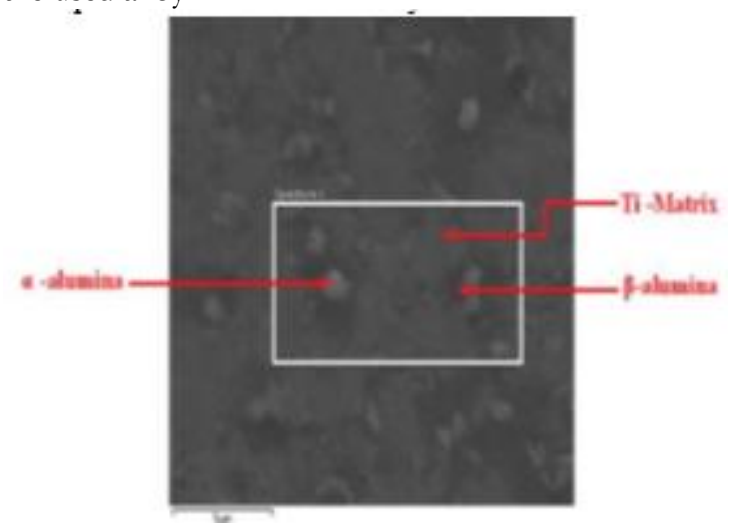

Figure (9): The SEM testing of the microstructure of Ti6Al4V include Alpha $(\alpha)$ and Beta $(\beta)$

Fig. (10) and Table (7). The relationship between the coating layer thickness and surface roughness indicates the highest thickness we can obtain $41 \mu \mathrm{m}$ when the roughness is 0.94 . These results are obtained under optimal conditions.

Figure (8): a. Shows the EDS and SEM testing while b. shows the Morphology and coating thickness of Ti6Al4V Substrate and Hap.

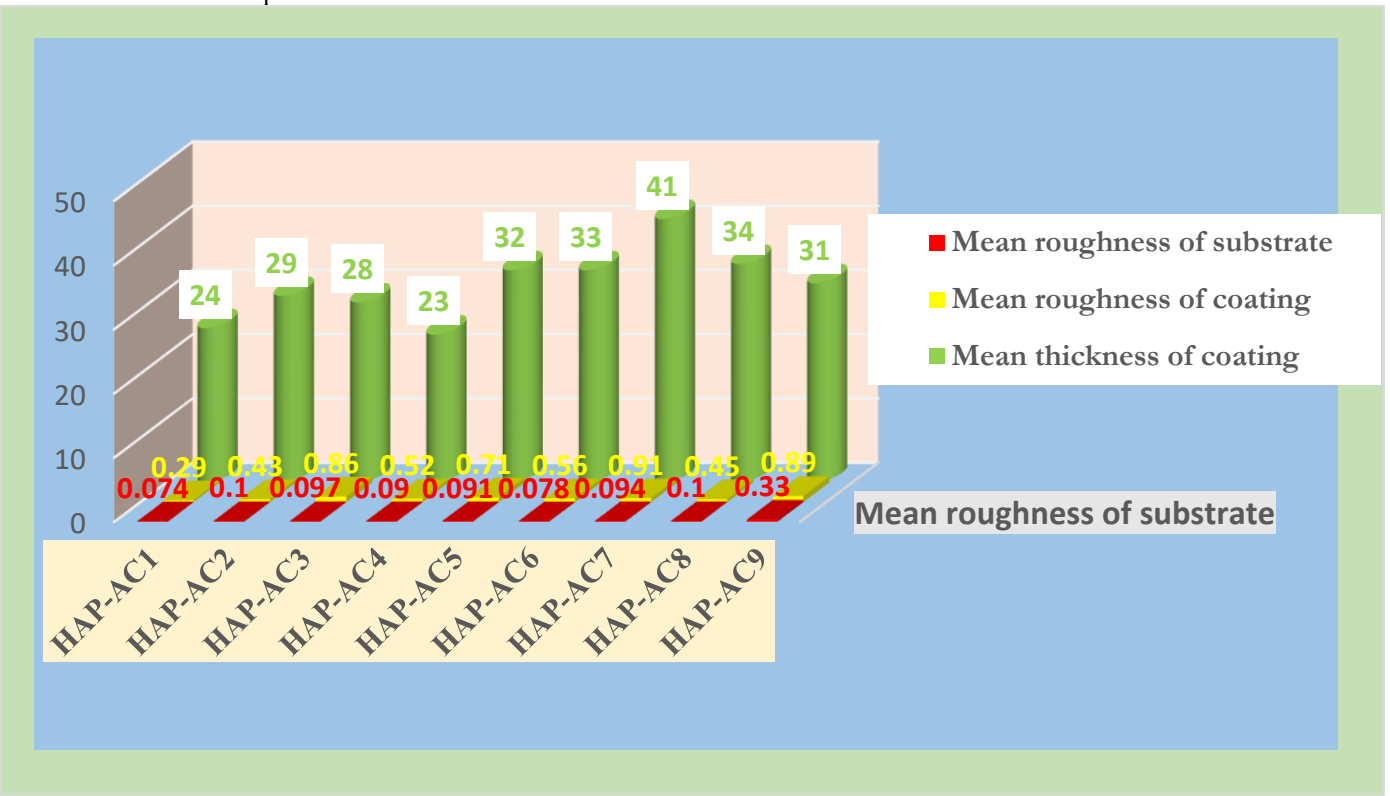

Figure (10): The relationship between the roughness and surface roughness of the substrate, the roughness of the coating and the thickness of the coating. 
Table (7): The relationship between surface roughness, sediment weight and coating thickness

\begin{tabular}{|c|c|c|c|c|c|}
\hline No & W0 & W1 & W0-W1 & $\begin{array}{c}\text { Mean } \\
\text { roughn } \\
\text { ess of } \\
\text { substra } \\
\text { te } \mu \mathrm{m}\end{array}$ & $\begin{array}{c}\text { Mean } \\
\text { thickn } \\
\text { ess of } \\
\text { coatin } \\
\mathbf{g} \boldsymbol{\mu m}\end{array}$ \\
\hline $\begin{array}{c}\text { HAP- } \\
\text { AC1 }\end{array}$ & 2.7241 & 2.7273 & 0.0032 & 0.74 & 24 \\
\hline $\begin{array}{c}\text { HAP- } \\
\text { AC2 }\end{array}$ & 2.7926 & 2.7962 & 0.0036 & 0.10 & 29 \\
\hline $\begin{array}{c}\text { HAP- } \\
\text { AC3 }\end{array}$ & 2.7119 & 2.7161 & 0.0041 & 0.97 & 28 \\
\hline $\begin{array}{c}\text { HAP- } \\
\text { AC4 }\end{array}$ & 2.7472 & 2.7511 & 0.0038 & 0.90 & 23 \\
\hline $\begin{array}{c}\text { HAP- } \\
\text { AC5 }\end{array}$ & 2.7885 & 2.7902 & 0.0052 & 0.91 & 33 \\
\hline $\begin{array}{c}\text { HAP- } \\
\text { AC5 }\end{array}$ & 2.7804 & 2.7851 & 0.0046 & 0.78 & 33 \\
\hline $\begin{array}{c}\text { HAP- } \\
\text { AC7 }\end{array}$ & 2.7452 & 2.7509 & 0.0057 & 0.94 & 41 \\
\hline $\begin{array}{c}\text { HAP- } \\
\text { AC8 }\end{array}$ & 2.7592 & 2.7524 & 0.0032 & 0.10 & 34 \\
\hline $\begin{array}{c}\text { AP- } \\
\text { AC9 }\end{array}$ & 2.7951 & 2.7986 & 0.0035 & 0.106 & 31 \\
\hline
\end{tabular}

The factors affecting on the distribution of the HAp coating layer using the EPD-AC method. It shows the effect of each of the two factors together as shown in Fig. 11.

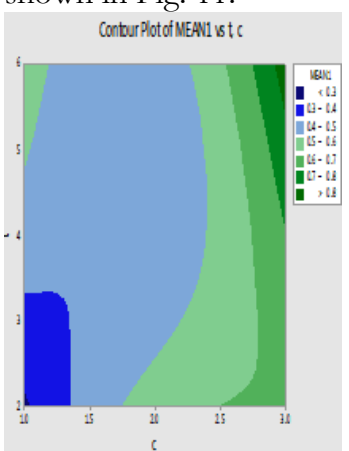

(a)

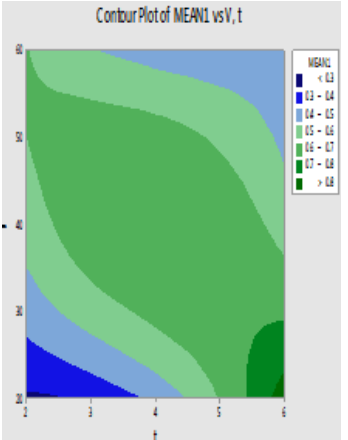

(b)

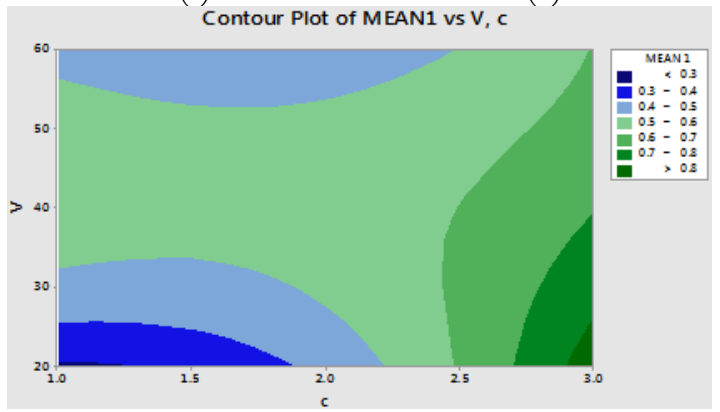

(c)

Figure (11): Effect of each of the two factors together on the distribution of the coating layer a) shows the effect of the concentration and the coating time of the coating b) illustrates the effect of the applied voltage and the coating time c) shows the effect of both the concentration and the applied voltage

\section{Conclusions}

1- The optimum conditions for EPD of hydroxyapatite coatings on Ti6Al4V depending on thickness are $40 \mathrm{~V}, 4 \mathrm{~min}$, and $2 \mathrm{~g} / \mathrm{L}$.
2- XRD analysis proved that EPD technique was suitable for Ti6Al4V alloy due to the existence of phase HAP coating.

3- Good stability was obtained with all solutions for deposition coatings which confirmed by zeta potential. The higher stability value of solution was found 21.74 for $100 \% \mathrm{HA}+0.5 \%$ chitosan.

4- Water contact angles for samples are altered between $75.448^{\circ}$ which considered as a hydrophilic to $38.132^{\circ}$ which considered as super a hydrophilic. These results are good in the initial stages where needs super hydrophilic surfaces.

5. Voltage, concentration and deposition time are the most important parameter in the electrodeposition process. Increased effort, concentration and coating times lead to increase overall growth, coating thickness, and surface coverage of samples

6- Roughness is an important factor as the thickness of the coating increases as the roughness increases.

\section{References:}

[1] M. Chellappa, U. Vijayalakshmi "Improved corrosion resistant and mechanical behavior of distinct composite coatings (silica/titania/zirconia) on Ti-6Al-4V deposited by EPD" Journal of Asian Ceramic Societies, Department of Chemistry, School of Advanced Sciences, VIT University, Vellore 632 014, Tamil Nadu, India (2017) .

[2] I. Gurappa* "Characterization of different materials for corrosion resistance under simulated body fluid conditions" Materials Characterization 49 (2002) 73 - 79.

[3] Katja M.R. Nuss and Brigitte von Rechenberg" Biocompatibility Issues with Modern Implants in Bone - A Review for Clinical Orthopedics" The Open Orthopaedics Journal, (2008), 2, 66-78.

[4] Mitsuo Niinomi "Mechanical biocompatibilities of titanium alloys for biomedical applications" Journal of the mechanical behavior of biomaterials V- 1 (2008) pp-30-42.

[5] Vasudeva D, shanmugam , B "Study of Thermal Behaviour On Titanium Alloys (Ti-6al-4v)" Journal of Engineering Science and Technology Vol. 12, No. 8 (2017) 2064 - 2077.

[6] Kazuhiro Imai, Xiao Zhou and Xiaoxuan Liu "Application of Zr and Ti-Based Bulk Metallic Glasses for Orthopaedic and Dental Device Materials "The University of Tokyo, Tokyo 1538902, Japan; (2020).

[7] Lothar W. Meyer · Lutz Krüger · Kristin Sommer 'Thorsten Halle-Matthias Hockau" Dynamic strength and failure behavior of titanium alloy Ti$6 \mathrm{Al}-4 \mathrm{~V}$ for a variation of heat treatments" Mech Time-Depend Mater (2008) 12: 237-247.

[8] M Kulkarni, A Mazare, E Gongadze, Š Perutkova, V Kralj-Iglič , I Milošev, P Schmuki , A Iglič and M Mozetič "Titanium nanostructures for biomedical applications "Nanotechnology 26 (2015) 062002 (18pp).

[9]Bartzsch, H.; Glöß, D.; Böcher, B.; Frach, P.; Goedicke, K'Properties of $\mathrm{SiO} 2$ and $\mathrm{Al} 2 \mathrm{O} 3$ films for electrical insulation applications deposited by 
reactive pulse magnetron sputtering" Surf. Coat. Technol. 2003, 174, 774-778.

[10] Mahtab Assadian · Mostafa Rezazadeh Shirdar - Mohd. Hasbullah Idris S. Izman Davoud Almasi Mohammad Mahdi Taheri Mohammed Rafiq Abdul Kadir " Optimisation of Electrophoretic Deposition Parameters in Coating of Metallic Substrate by Hydroxyapatite Using Response Surface Methodology" Research Article Mechanical Engineering(2015) pp1-11.

[11] M. Pourbaghi-Masouleh, H. Asgharzadeh "Optimization of sol-gel technique for coating of metallic substrates by hydroxyapatite using the Taguchi method "Materials Science-Poland, 31(3), 2013, pp. 424-433.

[12] Leila Sorkhi, , Morteza Farrokhi-Rad and Taghi Shahrabi " Electrophoretic Deposition of Hydroxyapatite- Chitosan-Titania on Stainless Steel 316 L" Surfaces 2019, 2, 458-467; doi:10.3390/surfaces2030034.

[13] J. Venugopal, Molamma P. Prabhakaran, Yanzhong Zhang, Sharon Low, Aw Tar Choon and S. Ramakrishna "engineering nanofibrous substrates for bone tissue Biomimetic hydroxyapatite-containing composite" a.royalsocietypublishing.org on July 16, (2014)pp1-18.

[14] A. Mohamed Hussein, M. Kumar, R. Drew and N. Al-Aqeeli "Electrochemical Corrosion and In Vitro Bioactivity of Nano-Grained Biomedical Ti20Nb-13Zr Alloy in a Simulated Body Fluid" (University, Montreal, QC H3G 1M8, Canada 2017) pp 1-15

[15] V Ozhukil Kollatha, Q Chen, R Closset, J Luyten, K Traina, S Mullensa, A R Boccaccinic and R Clootsb "AC vs. DC Electrophoretic Deposition of Hydroxyapatite on Titanium" (University of Erlangen-Nuremberg, Erlangen, German,2013) PP 04-030.

[16] dele Carradò, Nathalie Viart "Nanocrystal line spin coated sole gel hydroxyapatite thin films on Ti substrate: Towards potential applications for implants" Solid State Sciences 12 (2010) 10471050, France.

[17] M. Farrokhi-Rad "Electrophoretic deposition of hydroxyapatite nanoparticles in differed alcohols:

Effect of Tris(tris (hydroxyethyl) amino methane)as dispersant" Ceramics, University of Tabriz, Iran , 2016) PP 3361-3371.

[18] Aldo R. Boccaccini and Igor Zhitomirsky "A pplication of electrophoretic and electrolytic deposition techniques in ceramics processing" Current Opinion in Solid State and Materials Science-V 6 (2002) pp251-26.

[19] Mona Goudarzi, Farhad Batmanghelich*, Abdollah Afshar, Abolghasem Dolati, Golsa Mortazavi" Development of electrophoretically deposited hydroxyapatite coatings on anodized Nano tubular TiO2 structures: Corrosion and sintering temperature "Applied science 301(2014)250-257.

[20] Dinh Thi Mai Thanh, Pham Thi Nam, Nguyen Thu Phuong, Le Xuan Que, Nguyen Van Anh, Thai Hoang, Tran Dai Lam "Controlling the electrodeposition, morphology and structure of hydroxyapatite coating on 316L stainless steel" Material science and Engineering C 33(2013) 2037-2047 